\title{
Correction to: The role of machine learning in clinical research: transforming the future of evidence generation
}

\author{
E. Hope Weissler ${ }^{1 *}$, Tristan Naumann ${ }^{2}$, Tomas Andersson ${ }^{3}$, Rajesh Ranganath ${ }^{4}$, Olivier Elemento ${ }^{5}$, Yuan Luo $^{6}$, \\ Daniel F. Freitag ${ }^{7}$, James Benoit ${ }^{8}$, Michael C. Hughes ${ }^{9}$, Faisal Khan ${ }^{3}$, Paul Slater ${ }^{10}$, Khader Shameer ${ }^{3}$, Matthew Roe ${ }^{11}$, \\ Emmette Hutchison ${ }^{3}$, Scott H. Kollins ${ }^{1}$, Uli Broedl ${ }^{12}$, Zhaoling Meng ${ }^{13}$, Jennifer L. Wong ${ }^{14}$, Lesley Curtis ${ }^{1}$, \\ Erich Huang ${ }^{1,15}$ and Marzyeh Ghassemi ${ }^{16,17,18,19}$
}

\section{Correction to: Trials 22, 537 (2021) https://doi.org/10.1186/s13063-021-05489-x}

Following the publication of the original article [1], we were notified that current affiliations 17, 18 and 19 were erroneously added to the first author rather than the senior author (Marzyeh Ghassemi).

The original article has now been corrected.
Published online: 06 September 2021

\section{Reference}

1. Weissler, et al. The role of machine learning in clinical research: transforming the future of evidence generation. Trials. 2021;22:537. https:// doi.org/10.1186/s13063-021-05489-x.

\section{Author details}

'Duke Clinical Research Institute, Duke University School of Medicine, Box 2834, Durham, NC 27701, USA. ${ }^{2}$ Microsoft Research, Cambridge, MA, USA. ${ }^{3}$ AstraZeneca, Gothenburg, Sweden. ${ }^{4}$ Courant Institute of Mathematical Science, New York University, New York, NY, USA. ${ }^{5}$ Englander Institute for Precision Medicine, Weill Cornell Medical College, New York, NY, USA. ${ }^{6}$ Northwestern University Clinical and Translational Sciences Institute, Northwestern University, Chicago, IL, USA. ${ }^{7}$ Division Pharmaceuticals, Open Innovation and Digital Technologies, Bayer AG, Wuppertal, Germany. ${ }^{8}$ University of Alberta, Edmonton, Alberta, Canada. ${ }^{9}$ Department of Computer Science, Tufts University, Medford, MA, USA. ${ }^{10}$ Billion Minds, Inc., Seattle, WA, USA. "'Verana Health, San Francisco, CA, USA. ${ }^{12}$ Boehringer-Ingelheim, Burlington, Canada. ${ }^{13}$ Sanofi, Cambridge, MA, USA. ${ }^{14}$ Sanofi, Washington, DC, USA. ${ }^{15}$ Duke Forge, Durham, NC, USA. ${ }^{16}$ Vector Institute, University of Toronto, Toronto, Ontario, Canada. ${ }^{17}$ Department of Electrical Engineering and Computer Science, Massachusetts Institute of Technology, Cambridge, Massachusetts 02139, USA. ${ }^{18}$ Institute for Medical Engineering and Science, Massachusetts Institute of Technology, Cambridge, Massachusetts 02139, USA. ${ }^{19}$ CIFAR Al Chair, Vector Institute, Toronto, Ontario, Canada.

The original article can be found online at https://doi.org/10.1186/s13063021-05489-x

* Correspondence: Hope.weissler@duke.edu

'Duke Clinical Research Institute, Duke University School of Medicine, Box 2834, Durham, NC 27701, USA

Full list of author information is available at the end of the article

(c) The Author(s). 2021 Open Access This article is licensed under a Creative Commons Attribution 4.0 International License, which permits use, sharing, adaptation, distribution and reproduction in any medium or format, as long as you give appropriate credit to the original author(s) and the source, provide a link to the Creative Commons licence, and indicate if changes were made. The images or other third party material in this article are included in the article's Creative Commons licence, unless indicated otherwise in a credit line to the material. If material is not included in the article's Creative Commons licence and your intended use is not permitted by statutory regulation or exceeds the permitted use, you will need to obtain permission directly from the copyright holder. To view a copy of this licence, visit http://creativecommons.org/licenses/by/4.0/. The Creative Commons Public Domain Dedication waiver (http://creativecommons.org/publicdomain/zero/1.0/) applies to the data made available in this article, unless otherwise stated in a credit line to the data. 